\title{
O cristianismo primitivo como objeto da história cultural: delimitações, conceitos de análise e roteiros de pesquisa.
}

\author{
Early Christianity as subject of a cultural history: delimitations, \\ concepts of analysis and research routes.
}

Paulo Augusto de Souza Nogueira*

RESUMO

Este artigo levanta questões referentes às possibilidades e limites de se proceder a uma história cultural do cristianismo primitivo. São apresentadas algumas obras-chave que oferecem análises que tangenciam e antecipam questões da história cultural, como a história de doutrinas e ideias religiosas, psicologia histórica, história de práticas religiosas populares, entre outros. Em seguida são discutidas a terminologia do campo de estudos, a abrangência cronológica e o corpo de documentos. Por fim, propõe-se o estudo das categorias mentais do Cristianismo Primitivo e a consideração do mesmo como um sistema de linguagem, por meio do estudo de seus textos narrativos e ficcionais.

Palavras-chave: História cultural, cristianismo primitivo, cultura como sistema de linguagem, narrativa cristã primitiva.

ABSTRACT

This article raises questions about the possibilities and limits of a cultural history of Early Christianity. It presents some key-works that anticipate and come close to the questions of a cultural history, such as the history of religious ideas and doctrine, historical psychology, the history of popular religiosity, among others. In the following section, the article discusses the terminology of this research field, and the scope of its chronology and documentation. Finally, the article proposes the study of the "mental categories" of Early Christianity by means of its narrative and fictional texts and the understanding of it as a system of language.

Keyword: Cultural history, Early Christianity, culture as language, Early Christian narrative.

\footnotetext{
- Doutor em Teologia pela Universidade de Heidelberg (1991), pós-doutorado em História pela Unicamp. Professor titular da Pós-Graduação em Ciências da Religião da Universidade Metodista de São Paulo.
} 


\section{Introdução}

Apesar da ampla produção acadêmica exegética, teológica e historiográfica não há muitos trabalhos acadêmicos que tenham oferecido uma visão de conjunto do Cristianismo Primitivo (CP) ${ }^{1}$. Essa lacuna é tornada possível devido a pressupostos de duas correntes antagônicas que inviabilizam qualquer projeto de reconstrução histórica do CP. A primeira corrente entende que a história do cristianismo primitivo é equivalente, de alguma forma, à história do Novo Testamento. Ou seja, bastaria se estudar os livros que compõem o Novo Testamento para se ter acesso às informações históricas necessárias para a reconstrução do CP. Essa posição reflete os pressupostos de que a história equivale ao relato canônico e que as doutrinas e fatos históricos são passíveis de reconstrução a partir desse corpo documental. A segunda corrente entende que, ainda que o CP tenha produzido textos (fontes escritas) desde suas origens, não é possível reconstruir a partir deles, de forma satisfatória, o papel ocupado pelas comunidades cristãs no mundo antigo, suas práticas, seu ethos social, seu desenvolvimento institucional, entre outros. Além de quase não haver evidências materiais nos dois primeiros séculos, as fontes escritas são por demais fragmentárias e ficcionais. São fragmentárias no sentido de que cobrem apenas alguns aspectos da vida dos cristãos na sociedade greco-romana, em algumas regiões, e em perspectivas muito específicas. O elemento ficcional e imaginativo desses textos também conflita com os interesses de uma historiografia tradicional, interessada em fatos e instituições.

Nesse artigo delinearemos as possibilidades do estudo do CP na perspectiva da história cultural, considerando a ausência de evidências materiais e reconhecendo o caráter lacunar (literário) das fontes? Com esse objetivo levantaremos as seguintes questões:

a) Os elementos imaginativos e ficcionais dos textos do CP nos permitem estudar a sua história e as categorias mentais por meio das quais grupos de cristãos concebem o mundo? Sendo as fontes de caráter literário, seria possível examinar essas fontes a partir das perspectivas de seus gêneros literários?

b) Não seria necessário, dada a fragmentariedade das fontes do $\mathrm{CP}$, e dado o escopo de uma história cultural (estruturas de longa duração), ampliar a cronologia do estudo e o corpus documental? Ou seja: quais textos e até que limite cronológico?

c) Como inserir em estudos de história cultural a diversidade de grupos e tendências no CP, sem recair numa consideração atomista? É possível estudar os grupos considerados como "heréticos" em seus conflitos com outros grupos internos, ainda que inseridos na rede de discursos do CP?

\footnotetext{
1 Usaremos a abreviatura CP para "Cristianismo Primitivo" como um conceito aberto, em discussão no próprio corpo do trabalho.
} 
d) É possível resgatar memórias de práticas religiosas ao invés de ceder ao primado do doutrinal? Como resgatar e reconstruir hipoteticamente práticas mágicas, litúrgicas, ethos social, entre outros aspectos, a partir de textos de propaganda ou de caráter apologético? Como essas práticas religiosas coexistem com os elementos catequéticos e doutrinais de superfície, ainda mais quando podem estar em contradição com os mesmos?

e) Como estudar o CP como movimento religioso no Império Romano, sem repetir a prática teológica de considerá-lo como novidade absoluta? A despeito de suas tensões com a sociedade que tipos de interações e negociações o CP promoveu na sociedade mediterrânea?

\section{Aproximações}

Ainda que uma história cultural do CP seja um projeto a ser desenvolvido, há trabalhos que a tangenciam ou a anteciparam de alguma forma. Mencionaremos algumas perspectivas e obras de destaque:

a) Uma história literária e doutrinária do Cristianismo Primitivo. Parece-nos ser um paradigma dessa corrente a Introdução ao Novo Testamento, volume 2, de Helmut Köester (2005), que, apesar de refletir no nome uma introdução literária tradicional, oferece uma visão de conjunto de desenvolvimentos institucionais, expansão geográfica, produção literária e doutrinal. Essa obra também contribui para o estudo do $\mathrm{CP}$ ao inserir em sua discussão os textos apócrifos. Também merece destaque a Theologiegeschichte des Urchristentums (História da Teologia do Cristianismo Primitivo) de Klaus Berger (1994), que oferece uma detalhada análise das diferentes posições doutrinárias dos diversos grupos e correntes do cristianismo no primeiro século. Essa obra, no entanto, não consegue oferecer uma visão de conjunto do CP e em sua relação com a sociedade, restringindo-se a posições doutrinárias, num quadro cronológico mais restrito. Mais recentemente se destacaram obras que abordam as origens e trajetórias de devoção religiosa no Cristianismo Primitivo. Entre elas destacamos The Birth of Christianity. Discovering what Happened in the Years Immediately after the Execution of Jesus, de John Dominic Crossan (1998), How Jesus Became God: The Exaltation of a Jewish Preacher from Galilee de Bart Ehrman (2015), e a muito debatida obra Lord Jesus Christ. Devotion to Jesus in Earliest Christianity, de Larry Hurtado (2003). Nessas obras, no entanto, ainda nos encontramos no âmbito de história de ideias e doutrinas religiosas, sem uma articulação sistemática com os pressupostos e modelos culturais das sociedades em que essas ideias foram gestadas.

b) Propostas de interpretação cognitiva e psicológica do CP. Como modelo dessa abordagem nós citaremos as obras de Gerd Theissen, Die Religion der Ersten Christen. Eine Theorie des 
Urchristentums (A Religião dos Primeiros Cristãos: Uma Teoria do Cristianismo Primitivo, edição alemã de 2000) e Erleben und Verhalten der ersten Christen. Eine Psychologie des Urchristentums (Experiência e Comportamento dos Primeiros Cristãos. Uma Psicologia do Cristianismo Primitivo, edição alemã de 2007). Antecede essas duas obras a Psicologia Histórica do Novo Testamento de Klaus Berger (2011), que busca explorar experiências básicas (poder, identidade, conceito de temporalidade, entre outros) dos primeiros cristãos, restringindo-se às fontes canônicas. Trata-se de obras seminais, que caminham em direção a uma história cultural, sem lhe explicitar o caráter, uma vez que delineiam modos e categorias de apreensão de mundo.

c) Há outro projeto que oferece uma contribuição promissora na análise da temática, e que poderia complementar a perspectiva listada acima, intitulado: A People's History of Christianity, projeto coordenado por Denis R. Janz, que dedicou seus dois primeiros volumes ao Cristianismo nos primeiros séculos: Christian Origins (2010) e Late Ancient Christianity (2005). Eles foram coordenados por Richard Horsley e por Virginia Burrus, respectivamente. Esses volumes estão mais interessados em uma história de cristãos do que em uma história da igreja, mais em práticas religiosas do que em história de teologias. Nos diferentes ensaios são apresentados temas como: ficção, magia, mulheres, crianças, práticas litúrgicas, construção de identidades. Esses estudos se encontram na esteira de trabalhos inovadores da área que não estudam o cristianismo isoladamente, mas como parte de redes discursivas do Império Romano, utilizando-se de conceitos críticos das ciências da linguagem, dos estudos culturais e de gênero. Merecem destaque entre os expoentes nessa perspectiva os estudos de Judith Perkins: The Suffering Self (1995) e Roman Imperial Identities in the Early Christian Era (2008), entre outros trabalhos.

d) Na América Latina e no Brasil foram também realizados esforços no sentido de estudar a pluralidade de correntes dentro do CP. Vale destacar os números da Revista de Interpretação Bíblica Latino-Americana: Cristianismos Originários (RICHARD, 1996) e Cristianismos Originários Extra-Palestinos (PIXLEY, 1998). A proposta desses trabalhos seminais foi depois desenvolvida em numerosos artigos da mesma revista. No entanto, é importante lembrar que esses ensaios ainda não refletem um esforço de elaboração de uma história cultural. Há intuições aqui e ali, principalmente nas questões de gênero e de etnia, além das referentes ao caráter plural do movimento religioso. Mas não há um projeto coeso, prevalecendo uma tendência historiográfica tradicional, com ênfase em condicionamentos econômicos e políticos, considerados estruturais. $\mathrm{Na}$ área dos estudos da religião do Antigo Israel, no entanto, há um trabalho pioneiro: Uma História Cultural de Israel, de Júlio Zabatiero (2013).

Apesar do valor de todas as perspectivas acima apontadas, e pela abrangência de suas propostas, entendemos que uma história cultural do CP é um projeto que ainda se encontra em estágio inicial de desenvolvimento. Nesse artigo nos limitaremos a apresentar alguns pressupostos, delimitações e a elencar temas e cortes possíveis. Também o fazemos a partir da perspectiva de historiadores e intérpretes latino-americanos. Entendemos que especialistas em religião que provêm 
de contextos profundamente marcados por experiências e práticas religiosas sincréticas e das mais diferentes configurações e origens certamente têm algo a contribuir nessa perspectiva.

\section{Delimitações do Cristianismo Primitivo}

Há muitas dificuldades na definição dos limites da pesquisa acadêmica do período histórico das origens do movimento cristão, seja no que se refere à nomenclatura, à cronologia, às fontes e às relações deste com a história do mundo mediterrâneo, e do universo religioso do Império Romano. Iniciemos com uma questão elementar, porém complexa: Qual o nome mais adequado a este campo de estudos? Os nomes do objeto deste campo de estudo variam: Cristianismo Originário, Proto-Cristianismo (Urchristentum), Cristianismo Primitivo, Cristianismo Antigo, Novo Testamento, variações de alguns desses nomes no plural (Cristianismos Originários), entre outros. Eles são definidos a partir das perspectivas em que são analisados: história da igreja (instituição), história das doutrinas, história social, história da difusão geográfica do movimento religioso, etc.

Nos estudos de teologia tradicional convencionou-se chamar o campo de Novo Testamento, e da história maior que o envolve de contexto do Novo Testamento. As dificuldades com esta nomenclatura são óbvias e até mesmo admitidas pelos que a utilizam. Ela é, por princípio, anacrônica, uma vez que Novo Testamento é o nome dado ao conjunto de 27 escritos que os concílios eclesiásticos do IV século definiram como autorizados para o uso litúrgico e para a fundamentação do dogma. Um conceito definido de cânon só foi possível, portanto, após muitos debates, negociações e disputas que foram encerradas por meio da autoridade de concílios das igrejas mais poderosas do oriente e do ocidente, sob os auspícios de Constantinopla. As listas canônicas antigas quando confrontadas com a história do uso (ou desuso) dos textos só evidenciou que a definição do cânon do Novo Testamento constituía um remendo para chegar a uma lista mínima de textos aceitos pelas igrejas do ocidente e do oriente, mas que sequer garantia que todos fossem lidos e aceitos como autoridade no mesmo grau. Há autores que argumentam que os textos do Novo Testamento merecem mais atenção acadêmica do que outros textos do CP devido a sua superior qualidade teológica e literária, pelos menos na perspectiva do que chamam de "unidade interna" (HAHN, 2002, p.viii). Não creio que seja necessário nos estendermos na refutação desse critério subjetivo.

Se Novo Testamento é um conceito anacrônico e pouco científico para definir as fontes, o período e os processos históricos das origens do movimento cristão na antiguidade, o que dizer das nomenclaturas "cristianismo originário" ou "cristianismo das origens"? Sem dúvida neste período temos as primeiras manifestações do cristianismo na história, ainda que seja muito difícil dizer quando exatamente o movimento se iniciou. Teria se iniciado com a pregação de Jesus de Nazaré, 
na Galileia, no final dos anos 30? Ou teria tido efetivamente origem, como afirmam muitos pesquisadores, quando o movimento religioso passa a pregar não a mensagem que Jesus pregava, uma mensagem judaica, portanto, mas a ele mesmo como centro da mensagem? Onde e quando teria começado esta origem? Em Jerusalém, após a execução do profeta galileu e o anúncio de sua ressurreição por parte de seus discípulos? Ou quando as ideias religiosas sobre quem teria sido Jesus de Nazaré e qual a importância de sua atividade, tivessem já sido desenvolvidas e elaboradas, como, por exemplo, em Antioquia, entre judeus de língua grega, no início dos anos 40 ? Dar uma resposta satisfatória a estas questões não é tarefa fácil e remete a um denso e acirrado debate acadêmico. Não temos sequer certeza sobre quando o cristianismo passa a ser visto como uma religião independente do Judaísmo, do qual se originou e cuja simbologia religiosa herdou. (NOGUEIRA; FUNARI; COLLINS, 2010). Os estudos mais recentes tendem a considerar o processo de ruptura com o Judaísmo e a constituição de uma identidade própria no cristianismo como mais fluido, não definido com precisão cronológica e ideológica. É, portanto, devido ao fato de não termos consenso sobre o que constitui precisamente a archê que temos que adotar um conceito de CP aberto. Tampouco seria produtivo insistir exclusivamente numa ou noutra hipótese sobre a origem, pois consideramos mais adequado que uma abordagem histórica, literária e exegética do tema leve em consideração as rupturas, as transformações, os inícios e as continuidades, mesmo que ressignificadas, no caso, entre movimento profético de Jesus de Nazaré e comunidades cristãs helenistas, ou entre Judaísmo e Cristianismo. Essas tensões também são objeto de estudo e não devem ser excluídas a priori.

O problema central no conceito de origem aplicado a Cristianismo Originário e Cristianismo das Origens se desdobra em várias questões importantes: Qual o limite desse processo da origem? Esta nova pergunta nos insere num campo igualmente minado de pressupostos e de ideais, nem sempre evidenciados no debate. As origens se dão no momento em que outra coisa que não seja tão ligada ao momento mágico das origens emerja? O que definiria esta ligação com as origens? 0 que distinguiria um movimento religioso do outro, aquele de onde se origina para o novo movimento religioso? Em que limite externo se encerra o processo inicial? Quando o novo movimento religioso está plenamente caracterizado?

Estas perguntas se referem tanto aos inícios do movimento cristão, no seio do Judaísmo, quanto ao seu processo de consolidação. Vejamos os limites externos, quando o cristianismo das origens está supostamente consolidado. Quando alguém diz que o CP é delimitado pela relação com a tradição apostólica, temos a impressão de que está usando o conceito Cristianismo Originário como um substituto elegante e politicamente correto de Novo Testamento. Se há um conceito frágil em toda a discussão sobre a delimitação do que é originário esse é o de "apostólico". O que é apostólico? Vejamos algumas das dificuldades. A maioria dos discípulos de Jesus, os apóstolos, era iletrada. Portanto, qualquer coisa que tenham dito sobre Jesus, seu ensino e as origens do cristianismo foi transmitida por outras pessoas, seja na tradição oral ou nos escritos antigos. $\mathrm{Na}$ verdade, a grande maioria dos testemunhos sobre o cristianismo nas origens foi escrita por testemunhos não apostólicos, ou pelas gerações que se seguiram depois deles. Mesmo os 
testemunhos transmitidos sob o nome e autoridade dos apóstolos, o foram de forma pseudonímica. No Novo Testamento, no núcleo duro do que se considera testemunho apostólico, apenas as cartas de Paulo - um apóstolo não original, ou seja, que não foi seguidor de Jesus de Nazaré em sua missão na Galileia e na Judeia -, e apenas algumas delas, são de autoria dele mesmo, segundo a pesquisa crítica. Ou seja, as pretensas origens são contadas por gente que não estava lá nas origens. Há uma verve ficcional também nos testemunhos mais antigos do cristianismo.

Retomemos a nossa questão: até quando vão as origens, o processo de consolidação do movimento religioso? Boa parte da pesquisa parte do pressuposto de que o período histórico que chamam Cristianismo das Origens, e as fontes que a ele se referem, têm como limite a passagem do primeiro para o segundo século d.C. Se esta divisão em torno do ano 100 for mantida com rigor, temos motivos para suspeitar que se trata de fato de um substituto do conceito Novo Testamento. Mas se não é o ano 100 o divisor de águas, considerando que sejam elencadas fontes até o segundo século adentro, quais devem ser consideradas e quais não? Consideramos os Pais Apostólicos (Inácio de Antioquia, Policarpo, Didaqué, Pastor de Hermas, etc.), mas não consideramos Tertuliano? Consideramos Irineu de Lion, mas não consideramos Marcião? Ou seja, que tipo de cristianismo, e até que limite ideológico, nós consideramos parte do CP? Onde se encaixam neste conceito modelos de cristianismo tão díspares quanto os representados pelos pais da igreja e pelos círculos que foram caracterizados como heréticos pela historiografia tradicional?

Em especial se apresenta como problemático o conceito de Patrística, que não pode ser considerado como equivalente ao $\mathrm{CP}$, afinal, a grande produção dos Pais da Igreja se dá nos séculos IV e V, e segue até o final da antiguidade tardia. Mas há Pais da Igreja que fazem parte da produção cristã dos séculos II e III e que efetivamente exerceram forte influência e liderança sobre amplos grupos de cristãos na antiguidade. Mas mesmo no caso da patrística dos séculos II e III há dificuldades de inseri-la como fonte exclusiva ou central no quadro amplo de reconstrução do Cristianismo nas suas origens devido ao caráter erudito e, por vezes, dogmático da mesma. Não é sem motivo que nos estudos teológicos tradicionais se divide os estudos de cristianismo na antiguidade em Novo Testamento e Patrística, ainda que os limites entre um e outro possam variar, como por exemplo, na inclusão dos Pais Apostólicos nos estudos neotestamentários.

Uma corrente de historiadores do cristianismo na antiguidade encontrou uma solução que, apesar de brilhante, não resolve os problemas do estudioso, principalmente os do período mais antigo. Trata-se da criação e consolidação dos Early Christian Studies como campo de estudo e de publicação nas universidades europeias e norte-americanas. Segundo o capítulo de abertura do Oxford Handbook of Early Christian Studies (HARVEY; HUNTER, 2008), intitulado From Patristics to Early Christian Studies, de Elizabeth A. Clark (2008, p.7-41), devido à consolidação da área em departamentos universitários, periódicos especializados e sociedades científicas, deve-se considerá-la como a responsável pelo estudo do cristianismo no mundo antigo e na antiguidade tardia, no período de cerca de 100 d.C. até cerca de 600 d.C. A autora justifica o início no ano 100 d.C. devido ao fato de o período anterior ser abordado pelos estudos neotestamentários, os quais 
teriam se constituído num campo definido, organizado e com ampla produção e presença no meio universitário internacional. Apesar de a justificativa apresentada ter certo fundamento institucional, nos parece que o tema do ano 100 reaparece, mas pelo outro lado da divisa. O que é anterior é do âmbito bíblico, pertencente ao exegeta, lindado talvez com o cristianismo originário, mas fora do escopo da pesquisa do historiador do cristianismo na antiguidade e na antiguidade tardia. Retomase a cisão e especialização dos períodos históricos em prejuízo dos estudos de desenvolvimentos históricos e culturais. Remete-se, desta forma, ao Novo Testamento - um conceito anacrônico como a um espaço idílico e a-histórico, sem relação com os desenvolvimentos das comunidades cristãs e sua relação com a sociedade.

Temos, portanto, as delimitações do campo de estudos do primeiro cristianismo feitas pelos mais diferentes critérios, propondo de um lado ou de outro da cronologia o ano 100 e inícios do segundo século como o ponto de divisão dos processos históricos e das fontes de seu estudo. Para os exegetas tudo o que passa do ano 100 perderia seu poder de testemunho apostólico mais antigo, mais bem preservado, entrando em processos de interferências de tradições populares e sincréticas. Para os historiadores, as fontes anteriores ao segundo século os colocam diante de questões técnicas e de fontes fragmentadas que parecem ser mais bem estudadas pelo exegeta e suas ferramentas críticas. Campo bem delimitado, competências especificadas, assim estaria o tema do cristianismo no mundo antigo resolvido. Não é essa a nossa opinião.

\section{O Cristianismo Primitivo como um sistema de linguagem}

O cristianismo se origina como uma religião de movimentação geográfica, social e cultural intensas. Jesus de Nazaré e seus discípulos eram pregadores itinerantes que tinham como objetivo pregar sua mensagem a todo o povo de Israel. Mas eles também causaram escândalo por circular entre grupos sociais considerados impuros, como os estrangeiros, prostitutas, cobradores de impostos, etc. Em algum momento, entre a missão de Jesus na Galileia e os primeiros anos da vida das comunidades, a pregação dos seguidores de Jesus de Nazaré alcançou as comunidades judaicas da diáspora de grandes centros urbanos como, por exemplo, Antioquia, capital da província romana da Síria. Esta mobilidade geográfica, étnica e social era facilitada pelo dinamismo social e cultural da comunidade judaica de fala grega na diáspora. Já nos anos 40 é possível supor que a comunidade cristã de Antioquia fosse maior e mais representativa que a de Jerusalém, ainda que esta gozasse de maior prestígio entre os fiéis. Nos anos 50 grupos de cristãos, entre os quais Paulo de Tarso, desenvolvem de forma mais acentuada a missão aos gentios, fundando comunidades em lugares estratégicos da Ásia Menor, Macedônia, Grécia, Egito, Itália, entre outros, consolidando definitivamente o cristianismo gentílico. É fundamental que se reconheça que esta pregação missionária entre os gentios não era uma ação isolada de Paulo de Tarso, como dão a entender as 
fontes antigas e certa historiografia, mas um modo de ação consolidado desse grupo. Há um modelo de pregador judaico-cristão da primeira geração: bilíngue, multicultural, itinerante, urbano, praticante de uma religião de conversão e de êxtase religioso. Nos anos 60 , senão antes, já temos evidência da presença de comunidades cristãs em Roma, capital do império. A partir daí estas pequenas comunidades, ainda confundidas com sinagogas judaicas - e talvez ainda estivessem no seio delas - se inserem cada vez mais no mundo mediterrâneo e buscam ampliar os canais de comunicação com a sociedade.

A rapidez e a eficiência com que o $\mathrm{CP}$ se insere no mundo mediterrâneo e a agilidade com que ele promove diálogo cultural nos mostram que essa nova religião se apresenta como comunidade de culto que se articula como um sistema de linguagem. Pertencer ao CP implicava ser doutrinado em um conjunto de códigos - gestual, metafórico, de sistemas narrativos, entre outros - que incluíam: o aprendizado da complexa história da salvação (cuja fonte se encontrava na LXX: com seus personagens e eventos da história da religião judaica), as narrativas da ação do Cristo no mundo, seus nomes e metáforas de culto, a caracterização do tempo presente como tempo escatológico, a aquisição de um conjunto de expectativas sobre o final dos tempos, a caracterização do mundo existente e de suas estruturas a partir de um paradigma dualista, a organização dos membros desta nova religião como uma comunidade, família e politeuma, etc. Este conjunto de códigos era transmitido intensamente junto com a pregação sobre o messias Jesus. Estes elementos são codificados numa espécie de koiné básico que, apesar de suas diferenças e variantes internas - que não eram pequenas - mantinha as comunidades unidas por meio da produção de códigos visuais, rituais, práticas sociais e intensa produção textual.

Temos evidência e documentação sobre estes elementos apenas a partir dos escritos dos primeiros cristãos e de poucos testemunhos externos sobre eles. Infelizmente, não restaram vestígios sobre o cristianismo primitivo na cultura visual, em seus artefatos, arquitetura e em outras produções materiais dos séculos I e II. Temos que inferi-los de materiais posteriores (por exemplo, da arte paleocristã do século IV) ou imaginá-los a partir de sua rica produção literária. De fato, a existência dessa produção literária e sua intensidade é que são surpreendentes. Se reconhecermos que temos acesso a apenas um fragmento dessa produção, e sendo ele ainda considerável, tornase um fator distintivo do cristianismo a sua rica produção escrita, em diferentes gêneros literários.

Ao abordarmos a produção literária, chegamos ao cerne do problema da documentação para o estudo de história cultural do cristianismo primitivo. Neste conjunto de documentação - base para o estudo acadêmico do cristianismo das origens - podemos listar:

a) O Novo Testamento, que aqui deve ser considerado não como uma coleção de escritos mais verdadeiros ou mais autorizados para o estudo exegético e histórico-religioso do cristianismo primitivo, mas como textos de muita antiguidade, que gozaram de prestígio (medido pela transmissão textual) entre as comunidades e que, a posteriori, foram combinados e transmitidos como um corpo canônico. Nele encontramos a documentação mais antiga disponível sobre Jesus de Nazaré e as cartas (algumas delas certamente autênticas) do pregador mais importante na 
difusão do movimento cristão nas origens, Paulo de Tarso. Merece destaque o livro de Atos dos Apóstolos que nos anos 90 traz o primeiro relato organizado e articulado, a partir de diferentes tradições locais, da difusão da pregação cristã no mundo mediterrâneo. Ele combina características da novela grega e da história romanceada. O Novo Testamento também inclui o primeiro apocalipse cristão, o Apocalipse de João, que oferece a primeira grande narrativa do tempo escatológico na perspectiva desse novo grupo religioso. Para nosso propósito de estudar o CP na perspectiva da história cultural, o Novo Testamento é um conjunto de fontes fundamental: nele, para além da análise de fatores sociais e econômicos etc., temos acesso a elementos como estruturas narrativas, metáforas recorrentes, representações do corpo, valores e sensibilidades morais, geografia mítica e imaginária, conceito de tempo, etc.

b) Os escritos dos Pais Apostólicos. Trata-se do nome atribuído a escritos de muita antiguidade (dos anos 90 a meados do século II), produzidos por lideranças comunitárias (anônimas, como no caso da Didaquê, ou assinadas por bispos de importância, como Ignácio de Antioquia). Estes textos gozaram de tanto prestígio que alguns de seus escritos, como o Pastor de Hermas, por exemplo, circulavam junto com os textos do Novo Testamento, sendo considerados como parte dele. Os escritos dos Pais Apostólicos se diferenciam da patrística elaborada (Clemente de Alexandria, Orígenes, Tertuliano, entre outros), devido a seu caráter assistemático, pouco elaborado doutrinariamente e nível de escrita não erudito. Neles encontramos principalmente cartas, seguindo a tradição paulina de comunicação epistolar das lideranças com as comunidades. Também encontramos um relato de caráter autobiográfico, uma espécie de diário de sonhos e de visões enviadas a um escravo cristão em Roma, chamado Hermas. Nele encontramos, talvez pela primeira vez, um relato autobiográfico de sonhos de um escravo e sua interpretação. Não seria essa uma fonte preciosa, quando não única, não só para o estudo do cristianismo, mas para o estudo da subjetividade no mundo antigo?

c) Os textos apócrifos do Novo Testamento e as Atas dos Mártires. Os apócrifos receberam esse nome a posteriori, no processo de definição de cânon pela igreja antiga. Alguns destes textos (ou estratos desses textos) são de antiguidade comparável aos escritos considerados canônicos (como no caso do Evangelho de Tomé). Eles se caracterizam por desenvolverem os mesmos gêneros literários dos escritos do Novo Testamento: evangelhos, atos apostólicos (prákseis), cartas (dentro dos evangelhos) e apocalipses. Para efeito do estudo histórico-religioso, em geral, e para uma história cultural, em particular, estes documentos devem ser considerados como equivalentes em importância aos demais escritos do Novo Testamento. Ressaltamos: sua caracterização de apócrifos ("ocultos") ocorreu a posteriori, por parte de autoridades eclesiásticas, num âmbito de apologia e jurisprudência específico e que não afetou a difusão destes escritos nos três primeiros séculos. Ao contrário do que se possa imaginar, esses textos gozavam de grande popularidade entre as comunidades cristãs espalhadas pelo Mediterrâneo. Vale lembrar que muitos destes apócrifos sobreviveram apenas por meio de pequenos fragmentos, como é o caso, por exemplo, dos papiros de Oxyrhynchus, no Egito (BLUMELL; WAYMENT, 2015). Estes fragmentos de evangelhos perdidos têm um valor especial para a pesquisa devido ao fato de eles terem 
sobrevivido num suporte que reflete uso quotidiano, ou seja, foram encontrados junto com cartas privadas, contratos comerciais, listas de produtos, textos administrativos, etc. Eles são testemunhas preciosas da prática de leitura e de cultivo do texto entre círculos amplos de cristãos, fora dos grandes centros de poder do Mediterrâneo. Representam este poder de textualidade e de comunicação do cristianismo primitivo em ação.

Se nós ampliamos nosso conceito de CP como um movimento religioso cujo processo de estabelecimento se dá em um processo longo, de fluidez identitária (com o judaísmo e em relação às tensões internas) e na criação de uma ampla rede textual, podemos centrar nosso estudo do mesmo, em perspectiva histórico-cultural, em três aspectos:

a) A história cultural do cristianismo primitivo pode ser estudada prioritariamente por meio dos gêneros literários narrativos e imaginativos. Para o estudo de uma história cultural precisamos de acesso à cultura popular desse grupo, ou seja, como que as pessoas comuns, que aderiram ao cristianismo, estruturaram sua relação com o mundo e com o sagrado. Com que categorias elas o faziam? Entendemos que para estudar esse sistema semiótico, da cultura como uma linguagem de segundo grau, temos que, no âmbito de nossas fontes, quase todas de caráter literário, atentar aos gêneros literários. O cristianismo primitivo não só criou uma intensa rede textual, mas o fez em torno de gêneros híbridos, adaptados dos gêneros helenísticos (como a novela grega, a biografia antiga ou a história romanceada) e de gêneros judaicos (apocalipses, midraxes, coleções de ditos proféticos) e organizados em gêneros literários de fronteira, híbridos, com os quais expressam sua visão de mundo (NOGUEIRA, 2015).

b) O caráter imaginativo e ficcional das fontes, que se constitui em problema para uma historiografia tradicional, se torna um espaço privilegiado do estudo das formas de apreensão de mundo desse grupo na perspectiva de uma história cultural. É necessária aqui uma palavra sobre o conceito de ficcionalidade ${ }^{2}$. Trata-se de um processo narrativo por meio do qual textos orais e literários jogam com tradições e normas de uma dada sociedade. Segundo Iser, em um texto ficcional as normas que são dadas como verticais, ou seja, hierarquicamente estabelecidas, são "horizontalizadas", são dispostas de formas alternativas (ISER, 1975, p.14). Essa é uma característica da literatura: poder inserir alusões às tradições em novos contextos, e inverter e subverter normas sociais. Os textos ficcionais desempenham um papel fundamental na cultura ao explicitarem que a forma como uma sociedade se organiza é apenas uma possível, que outras normas, outros agentes sociais, em inusitadas combinações são possíveis, pelo menos, no nível das narrativas. Quando estudamos as formas como um grupo social se projeta em narrativas ficcionais, adentramos o universo cultural dos sujeitos que se movem em meio a desejos e medos, tentando remodelar sua realidade por meio de suas frágeis, mais flexíveis redes textuais. Para uma historiografia centrada nos sujeitos, esses textos são objetos prioritários de estudo. O elemento ficcional perpassa os Evangelhos, Atas e Apocalipses, canônicos ou apócrifos. O primado do

\footnotetext{
${ }^{2}$ Para uma discussão do conceito de ficcionalidade ver Nogueira (2015, p.115-142).
} 
narrativo, do ficcional e do imaginativo sobre o doutrinal é um critério fundamental para uma história cultural do CP.

c) Adoção de uma cronologia longa e foco no estrato intermediário. Se não podemos nos restringir aos escritos produzidos no período idealizado do primeiro século, de um período das supostas origens apostólicas, das doutrinas e testemunhos ainda não tocados por dissensões e sincretismos, nós temos que trabalhar com uma cronologia ampla. Se nós consideramos o cristianismo primitivo como um sistema de linguagem, de comunicação de práticas, memórias, ensinos, e de administração interligada das comunidades, temos que considerar o quadro cronológico em que este sistema de linguagem se torna minimamente configurado, a ponto de ter uma linguagem reconhecível (vocabulário, gêneros, repertório de memórias) e diferenças internas na mesma (para evitar que este sistema seja redundante). Nesta concepção, a longa duração, a variação geográfica, a existência de gêneros fixos e a conflitividade do discurso são elementos fundamentais para a análise. $O$ fato de nosso corpo de textos (listado acima) se estender por quase três séculos não é um empecilho para a acuidade da análise, pelo contrário, permitirá analisar os textos mais antigos em processos de recepção nos que se seguem, analisará não ações e palavras primeiras isoladamente, mas em seu efeito e impacto na sociedade e na cultura. As redes textuais são mais importantes do que as palavras isoladas.

A escolha de uma data específica para delimitar o final de um período histórico e de um conjunto de fontes é sempre artificial. Afinal, as formas de espiritualidade, de ensino, de práticas religiosas são sempre desenvolvidas, apesar das rupturas, em temporalidades diversas. Mas se tivermos que escolher um período de delimitação dos estudos do $\mathrm{CP}$, deveríamos ficar com a data limite de 313 d.C., com o Edito de Milão, do imperador Constantino, no qual ele torna o cristianismo uma religião reconhecida pelo poder imperial, isentando-o de condenação jurídica e de ameaças de perseguição. Não se trata apenas do fim de um período heroico de resistência dos mártires cristãos, mas do início de um processo no qual os bispos cristãos das principais cidades do império passam a gozar de prestígio social, de poder político e de um tipo de influência na sociedade que era impensável até então. No período que se segue a este edito o cristianismo também toma rumos diferentes daqueles de seus primeiros fundadores, passando a elaborar padrões doutrinários, rituais e arquitetônicos distintivos. Não se trata da adoção de uma cronologia ampliada apenas. Devemos ressaltar que não temos como foco fatos, mas processos culturais, desenvolvimentos de modelos cognitivos, formação de narrativas e imagens estruturantes. Nesse sentido a cronologia não é mais do que uma referência.

Quando nos referimos ao estrato intermediário da cultura, referimo-nos a uma escrita que reflete, de alguma forma, a cultura popular, oral e as práticas religiosas cotidianas. É intermediária por ser escrita, portanto produto de pequenos artesãos, burocratas, escribas, comerciantes que, em grego koiné e em gêneros literários híbridos e adaptados, nos abrem janelas preciosas para as práticas e estruturas mentais de homens e mulheres no cristianismo na antiguidade. 


\section{Categorias mentais}

Temos que abordar o conceito de "categorias mentais" ou de "visão de mundo" à qual remete a história cultural e quais as dificuldades e especificidades da aplicação desse conceito ao estudo do CP. Como observa Aaron Gurevich (1985, p.16), que tomamos como referência nesse campo, há uma dificuldade implícita em todo esforço de estudo de categorias mentais de sociedades do passado remoto. Elas são difíceis de serem apreendidas por nós, além de ser impossível não contaminarmos nossas análises com nossas próprias preferências, perspectivas e categorias. Há também a dificuldade em escolher quais categorias analisar. O que é importante estudar? $\mathrm{Na}$ análise das categorias mentais do mundo medieval, Gurevich $(1985$, p.17) escolhe as seguintes: tempo, espaço, lei, trabalho e riqueza. Há, portanto, categorias do âmbito cósmico e da ordem social. A forma como elas se relacionam entre si é de grande valor, uma vez que elas têm que se configurar como um sistema. A escolha das categorias, no entanto, não deve ser absoluta: elas são portas de entrada nesse sistema da cultura. A partir daí todas devem se relacionar entre si. A cultura é organizada, nessa perspectiva, como um sistema semiótico, que não apenas se manifesta na linguagem, mas que se articula como um sistema de linguagem. Elas são a base da percepção de mundo de uma sociedade e nesse sentido são universais. São as formas como as pessoas percebem, organizam, classificam e valoram o real. Apesar de sua universalidade, mas devido a sua importância, essas percepções são manipuláveis pelo poder. Dominar categorias de percepção de mundo é uma forma estratégica de exercer poder. Essas formas de percepção são, no entanto, tão fundamentais que mesmo os que as controlam não se encontram isentos de seu poder de formação da realidade. Essa rede textual é estruturante.

No entanto, há dificuldades inerentes ao estudo das categorias mentais em nosso campo de estudo. $\mathrm{O} \mathrm{CP}$ em nenhum estágio do seu desenvolvimento representa e equivale à cultura de sua sociedade, como viria a ser no período Bizantino ou na Idade Média. Isso significa que o estudo da história cultural do cristianismo primitivo só pode ser parte de um projeto maior do estudo da história cultural do Mediterrâneo sob o Império Romano. Por outro lado, ao estudarmos suas categorias mentais, o entendemos como um sistema cultural semiautônomo. Se a cultura maior for uma linguagem, o subsistema seria um dos seus dialetos. Entendemos que o Cristianismo Primitivo, apesar de ser um fenômeno cultural, social e religioso do Império Romano, não podendo ser estudado isoladamente em relação a este, também desenvolve um sistema semiológico próprio, mesmo que em tensão com as vertentes centrais da cultura. Ele se porta como uma linguagem fronteiriça, que busca ressignificar a realidade social a partir de uma nova semântica e de novas formas versar sobre o mundo. O estudo das categorias mentais do CP teria diante de si algumas possibilidades:

a) $\mathrm{O}$ estudo de categorias fundamentais como tempo, espaço, identidade, corpo e corporeidade, sexualidade, etc. Em cada uma dessas categorias haveria que se perguntar pelas 
superposições e diferenças em relação ao sistema cultural maior. Nos esquemas de espaço e tempo (esquemas cronotópicos), nas narrativas do CP, estão incluídas as narrativas de perigos e aventuras, viagens a lugares e países exóticos, geografia do além-mundo e os deslocamentos escatológicos do tempo. É nesses espaços e tempos narrativos que se constroem as noções de sujeito nessas narrativas.

b) O estudo de categorias mais específicas do grupo, que the destacam a marginalidade, em especial nas formas de experiência religiosa, como a profecia, o êxtase, a visão, a conversão, etc. Trata-se de problematizar a própria linguagem e as expressões dessa problematização nas fontes: linguagem como "revelação", o êxtase e o sonho como estruturadores da palavra, a profecia e o oráculo, e as formas da interpretação, da alegoria, da Escritura (LXX) como meio de leitura do presente e da história.

Entendemos ainda que, se o CP se configura como um sistema semiótico e, dessa forma, se constitui numa linguagem da cultura, deve ser estudado em suas próprias formas de expressão. Encontramos analogias desse procedimento em outro livro de Aaron Gourevitch (1990, p. 1-38), no qual ele propõe acessos privilegiados às estruturas da cultura popular por meio da hagiografia, das narrativas de visões do mundo do além e da iconografia dessas visões, dos penitenciais, e dos exempla. É nesses gêneros narrativos (em alguns casos provenientes da oralidade), litúrgicos e visuais que as percepções da cultura popular medieval se manifestam e podem ser analisadas. Em nossa opinião, essa perspectiva também se aplica ao estudo do CP: em suas formas narrativas, metafóricas e gestuais, conforme já apontamos acima. Se adaptarmos o esquema proposto por Gurevich, de estudar não apenas as categorias, mas as formas como elas são expostas, podemos inserir no modelo de análise o conceito de cronotopos: tempo e espaço são formas narrativas de constituição do sujeito numa dada sociedade, num dado período histórico (BAKHTIN, 2008, p.84258). As formas de narrativa são fundamentais para o estudo desse espaço-tempo. Temos que revisitar Bakhtin para fins de uma história cultural do CP. Uma história cultural do CP tem, portanto, que explorar os gêneros literários e discursivos. E nesse contexto, em um sistema de linguagem as suas formas fronteiriças são fundamentais. Essas formas estão presentes, a meu ver, nas articulações do grotesco, do bizarro, do híbrido e do onírico. São formas nas quais a linguagem aponta para o desconforto diante do estabelecido, forçando as percepções culturais para os limites, para novas classificações.

Diante do exposto, propomos o estudo de uma história cultural do CP que leve em conta dois aspectos:

a) $\mathrm{O}$ fato de que as categorias mentais estão em transformação, afinal O CP promove alterações no sistema ao propor novas formas de apreensão do real.

b) Essa transformação se dá em processos lentos, de longa duração. Isso reforça nosso argumento, apresentado acima, de que devemos estudar o CP na longa duração, com um conjunto 
amplo de fontes. Nelas estudamos construções persistentes e variantes. Não pode haver pura redundância.

\section{Conclusões}

Nesse artigo nos perguntamos pelas possibilidades do estudo do CP por meio da perspectiva da história cultural. Iniciamos nosso argumento apontando para estudos relativamente recentes e outros contemporâneos nos quais perspectivas pertinentes a essa perspectiva são levantadas. Há esforços acadêmicos que contemplam a pesquisa da história de doutrinas e ideias religiosas, de estudos sobre o pluralismo dentro do $\mathrm{CP}$, de análises na perspectiva da psicologia histórica e das representações e das práticas religiosas das camadas populares. Essas perspectivas tangenciam em vários aspectos, sem, no entanto, explorar plenamente as questões relativas a uma história cultural.

Também levantamos questões preliminares, mas fundamentais, para o estudo da história cultural do CP. Começamos pela própria definição desse campo de estudos que, às vezes, por falta de precisão, se confunde com os estudos de Novo Testamento, ou com idealizações do que teria sido o cristianismo originário. Insistimos numa definição aberta do campo, em torno do nome "cristianismo primitivo" (CP). Entendemos que essa designação evita confusão com o estudo de história de doutrinas em formatos canônicos e ajuda a causar certo estranhamento frente às fontes, sem buscar qualquer origem mágica no passado. Se, por um lado, tivemos que nos diferenciar das delimitações teológicas desse campo de estudos, por outro lado, insistimos na necessidade de rejeitar a classificação adotada na academia nos países do Atlântico Norte que delimita os estudos na datação, para nós arbitrária, do ano 100 d.C. (em Novo Testamento antes e estudos de "cristianismo antigo" depois). Nossa proposta é a de rejeição de critérios canônicos, de autoridade supostamente apostólica e de cronologia estreita, uma vez que pretendemos privilegiar processos de longa duração e a análise de uma complexa e plural rede textual, que permita entender a história cultural dos estratos intermediários do CP tal como articulados num sistema de linguagem nas margens da sociedade mediterrânea.

Para empreender essa análise empregamos conceitos e conjuntos de questões da história cultural, tal como desenvolvida por Aaron Gurevich para o período medieval. Ele privilegia uma compreensão semiótica da cultura de uma sociedade, por meio do estudo de categorias mentais que permitem articular o social e o cósmico, categorias específicas e outras mais universais. Ele também oferece uma perspectiva importante para o estudo da cultura popular por meio da abordagem prioritária de fontes dos estratos intermediários (ou seja, letrados, porém representativos de amplas camadas da população) levando em consideração certos gêneros literários, visuais e 
litúrgicos. No caso do CP entendemos que, na ausência de evidências materiais e visuais até o século IV, os gêneros literários híbridos criados pela literatura neotestamentária e apócrifa são as portas de acesso privilegiado a essas categorias. É em especial nas redes metafóricas, nas formas de narração e de articulação imaginativa e ficcional que podemos estudar as categorias mentais do CP.

Procedemos, dessa forma, a uma delimitação ampla de cronologia (até 313 d.C.) e de fontes literárias (Novo Testamento, literatura apócrifa e Pais Apostólicos, entre outros), enfatizando, no entanto, que essas delimitações jamais pretendem restringir em seus âmbitos processos históricos multifacetados, dinâmicos e plurais. No corpo dessa discussão apenas mencionamos alguns outros aspectos que merecem nossa atenção e que pretendemos desenvolver em ensaios futuros, como os aspectos fronteiriços da linguagem dos primeiros cristãos, em processos sincréticos de tradução nas bordas da cultura mediterrânea, com os mais variados interlocutores. Também apontamos brevemente para o fato de que as formas narrativas e imagéticas (metafóricas) do bizarro e do grotesco, que enfrentam tanta resistência ou desprezo do exegeta e do historiador, devem ocupar um lugar central nesses estudos.

\section{Referências}

BAKHTIN, M. M. The Dialogic Imagination. Four Essays. Austin: University of Texas Press, 2008.

BERGER, Klaus. Psicologia histórica do Novo Testamento. São Paulo: Paulus, 2011.

BERGER, Klaus. Theologiegeschichte des Urchristentums. Theologie des Neuen Testaments. Tübingen: UTB, 1994.

BLUMELL, Lincoln H.; WAYMENT, Thomas A. (Ed.). Christian Oxyrhynchus. Texts, Documents, and Sources. Waco: Baylor University Press, 2015.

BURRUS, Virginia (Ed.). Late Ancient Christianity (A People's History of Christianity). Minneapolis: Fortress Press, 2005.

BURRUS, Virginia. Word and Flesh: The Bodies and Sexuality of Ascetic Women in Christian Antiquity. Journal of Feminist Studies in Religion, v. 10, n. 1, Spring, p. 27-51, 1994.

CASTELLI, Elizabeth. Martyrdom and Memory: Early Christian culture making (Gender, Theory, and Religion). Columbia: Columbia University Press, 2007. 
CHEVITARESE, André L. Cristianismos. Questões e debates metodológicos. Rio de Janeiro: Kliné, 2011.

CLARK, Elizabeth A. From Patristics to Early Christian Studies. In: HARVEY, S. A.; HUNTER, D. G. Oxford Handbook of Early Christian Studies. Oxford: Oxford University Press, 2008.

COHEN, Shaye J. D. The Beginnings of Jewishness. Boundaries, Varieties, Uncertainties. Berkeley: University of California, 1999.

COX MILLER, Patricia. The Corporeal Imagination. Signifying the Holy in Late Ancient Christianity. University of Pennsylvania Press, 2009.

CROSSAN, John Dominic. The Birth of Christianity. Discovering what Happened in the Years Immediately after the Execution of Jesus. San Francisco, 1998, 656p.

CUCHE, Denys. A noção de cultura nas ciências sociais. Bauru: EDUSC, 1999.

EHRMAN, Barth. How Jesus Became God: The Exaltation of a Jewish Preacher from Galilee. New York: HarperOne, 2015.

GUREVICH, Aaron, J. Categories of Medieval Culture. London/Boston: Routledge \& Kegan Paul, 1985.

GOUREVITCH, Aaron. Medieval Popular Culture. Problems of Belief and Perception. Cambridge: Cambridge University Press, 1990.

GUREVITCH, Aaron. A síntese histórica e a Escola dos Anais. São Paulo: Perspectiva, 2003.

HAHN, Ferdinand. Theologie des Neuen Testaments: Band 1: Die Vielfalt des Neuen Testaments (Theologiegeschichte des Urchristentums). Tübingen: Mohr\&Siebeck, 2002.

HARVEY, S. A.; HUNTER, D. G. Oxford Handbook of Early Christian Studies. Oxford: Oxford University Press, 2008.

HORSLEY, Richard (Ed.). Christian Origins. (A People's History of Christianity). Minneapolis: Fortress Press, 2010.

HURTADO, Larry. Lord Jesus Christ. Devotion to Jesus in Earliest Christianity. Grand Rapids: Eerdmans, 2003.

ISER, Wolfgang. The Reality of Fiction: A Functionalist Approach to Literature. In: New Literary History, vol.7, n.1, 1975, p.7-38. 
KÖESTER, Helmut. Introdução ao Novo Testamento. História e literatura do cristianismo primitivo. São Paulo: Paulus, 2005. v. 2.

MEEKS, Wayne A. Os primeiros cristãos urbanos: o mundo social do apóstolo Paulo. São Paulo: Paulinas, 1992.

MOSS, Candida. Ancient Christian Martyrdom: Diverse Practices, Theologies, and Traditions. New Haven: Yale University Press, 2012.

NOGUEIRA, Paulo A. S.; FUNARI, Pedro P A.; COLLINS, John. J. (Ed.). Identidades fluídas no judaísmo antigo e no cristianismo primitivo. São Paulo: Annablume, Fapesp, 2010.

NOGUEIRA, Paulo A. S. Experiência religiosa e crítica social no cristianismo primitivo. São Paulo: Paulinas, 2003.

NOGUEIRA, Paulo A. S. Religião e Linguagem. Abordagens teóricas interdisciplinares. São Paulo: Paulus, 2015.

NOGUEIRA, Paulo A. S. Traduções do intraduzível. A semiótica da cultura e o estudo de textos religiosos nas bordas da semiosfera. Estudos de Religião, v.29, n.1, p. 102-123, 2015.

PERKINS, Judith. The Suffering Self: pain and narrative representation in the early Christian era. London: Routledge, 1995.

PERKINS, Judith. Roman Imperial Identities in the Early Christian Era. London: Routledge, 2008.

PIÑERO, Antonio (Ed.). Origenes del Cristianismo. Antecedentes y primeros pasos. 2. ed. Cordoba: Cristiandad, 1995.

PIXLEY, Jorge (Ed.). Cristianismos Originários Extra-palestinos (35-138 d.C.). Revista de Interpretação Bíblica Latino-americana. Petrópolis, v. 29, 1998.

PIXLEY, Jorge (Org.). A canonização dos escritos apostólicos. Revista de Interpretação Bíblica Latino-americana, Petrópolis, v. 42/43, 2002.

RHEE, Helen. Early Christian Literature. Christ and Culture in the Second and Third Centuries. New York: Routledge, 2005.

RICHARD, Pablo (Ed.). Cristianismos Originários (30-70 d.C.). Revista de Interpretação Bíblica Latino-americana, Petrópolis, 22, 1996.

ROWLAND, Christopher. Christian Origins. An Account of the Setting and Character of the most Important Messianic Sect of Judaism. 2. ed. London: SCM, 2002. 


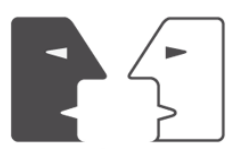

ANTÍTESES

THEISSEN, Gerd. Die Religion der ersten Christen. Eine Theorie des Urchristentums. Gütersloh: Gütersloher Verlagshaus, 2000.

THEISSEN, Gerd. Erleben und Verhalten der ersten Christen. Eine Psychologie des Urchristentums. Gütersloh: Gütersloherverlagshaus, 2007.

ZABATIERO, Júlio P. T. Uma história cultural de Israel. São Paulo: Paulus, 2013.

recebido em 03.08.2015 - aprovado em 26.10.2015 